\title{
Evaluation of Photocatalytic Active Coatings on Sintered Glass Tubes by Methylene Blue
}

\author{
Colin Awungacha Lekelefac, ${ }^{1}$ Peter Czermak, ${ }^{2,3,4}$ and Michael Herrenbauer ${ }^{1}$ \\ ${ }^{1}$ University of Applied Sciences Mittelhessen, Laboratory of Material Science, Surface Interface and System Design, \\ Wiesenstraße 14, 35390 Giessen, Germany \\ ${ }^{2}$ University of Applied Sciences Mittelhessen, Institute of Bioprocess Engineering and Pharmaceutical Technology, \\ Wiesenstraße 14, 35390 Giessen, Germany \\ ${ }^{3}$ Department of Chemical Engineering, Faculty of Engineering, Kansas State University, Manhattan, KS 66506, USA \\ ${ }^{4}$ Department of Chemistry, Faculty of Biology and Chemistry, Justus-Liebig-University Giessen, 35392 Giessen, Germany \\ Correspondence should be addressed to Peter Czermak; peter.czermak@kmub.thm.de
}

Received 12 May 2013; Revised 11 September 2013; Accepted 14 September 2013

Academic Editor: Niyaz Mohammad Mahmoodi

Copyright @ 2013 Colin Awungacha Lekelefac et al. This is an open access article distributed under the Creative Commons Attribution License, which permits unrestricted use, distribution, and reproduction in any medium, provided the original work is properly cited.

\begin{abstract}
A comparative study between ten different photocatalytic active coatings was done. The effectiveness and photocatalytic activity of the coatings were studied by degradation experiments of methylene blue (MB) dye under UV light illumination. The reactor design consisting of sintered glass packed in a borosilicate tube placed between two planar dielectric barrier discharge lamps (Osram Planon) is reported for the first time. The coatings consisted of either titania, silica, or zinc on sintered borosilicate glass. The advantage of sol-gel in catalyst preparation was exploited to combine catalyst to act as cocatalyst. $\mathrm{TiO}_{2}-\mathrm{P} 25$ widely applied in suspension systems was effectively immobilized on sintered glass support with the aid of tetraethylorthosilicate (TEOS) solution which acted as support material. Results indicated that $\mathrm{TiO}_{2}-\mathrm{P} 25+\mathrm{SiO}_{2}, \mathrm{TiO}_{2}-\mathrm{P} 25+\mathrm{SiO}_{2}+\mathrm{Pt}$, and $\mathrm{TiOSO}_{4} 30,6$ wt $\%$ films showed highest degradation rates close to $100 \%$ after 90 min illumination with degradation rates exceeding $50 \%$ after 30 minutes. TTIP+Pt showed lowest degradation rate.
\end{abstract}

\section{Introduction}

The textile and chemical industry face the challenge to adequately dispose their waste water. Releasing chemicals and colored waste water in the ecosystem is a source of pollution and damage to aquatic life. In order to treat waste water physicochemical methods such as adsorption [1], chemical methods such as chlorination and ozonation [2], and biological methods [3] are the most frequently used approaches. The catalytic system can either be homogeneous or heterogeneous. In a heterogeneous system, both adsorption and photocatalysis take place and have major advantages such as reuse of catalyst; minimization of catalyst leaching or resistance to extreme physical and chemical conditions. A heterogeneous system is tested in this study with use of coatings produced through sol-gel basis on sintered glass in a borosilicate glass tube.
Currently most photocatalytic reactors used for water treatment are suspension reactors with the advantage of high catalytic efficiency [4]. However, the catalyst particles have to be recovered after reaction through means such as ultrafiltration which bring along an additional process step and higher cost. Also, particulate matter may accumulate in the reactor during the concentration of a process effluent. Due to these reasons, a photocatalytically active layer on a support material is of growing interest. The setbacks of immobilized system are the less photonic efficiency values attained compared to suspension reactors because of mass transfer limitation [5]. For a good catalytic efficiency in an immobilized catalytic system, a good fluidic design of the system and extensions using the visible spectrum by catalyst doping can be of great importance. The selection and design of the supporting material influence both the fluidic design 
and the available catalyst surface. The photocatalytic efficiency increases with an increase in active surface. This means the carrier material has to provide a high surface to volume ratio. In this work, the use of coated sintered glass particles is to exploit both the advantages of a heterogeneous system and to obtain an optimal fluidic design by use of porous glass. The reactor design consisting of sintered glass with pore size between 150 and $250 \mu \mathrm{m}$ and glass particle grain size between 200 and $400 \mu \mathrm{m}$ packed in a borosilicate tube placed between two planar dielectric barrier discharge lamps (Osram Planon) is reported for the first time.

Tinanyloxysulphate precursor used in this study had been reported by Hidalgo et al. [6, 7] to yield high photonic efficiency of $4-7 \%$. This is a higher value as that obtained by Chen and Ray [8] who describes a suspension system. The aim of the study was to develop other catalysts systems and test their photocatalytic degradation efficiency with MB dye. Catalyst preparation in this study was via sol-gel route. Sol-gel route is a wet-chemical process with many advantages. The sol-gel offers simplicity in synthesis of sols, homogeneity of coatings, and ability to deposit coatings on larger and oddshaped substrates. Furthermore, a simple modification of the film composition can be performed directly in the sol-gel process.

Photocatalysis is the acceleration of a photoreaction in the presence of a catalyst. In a heterogeneous photocatalytic system, photo induced molecular transformations or reactions take place at the surface of a catalyst. Depending on where the initial excitation occurs, photocatalysis can be generally divided into two classes of processes [9]. When the initial photoexcitation occurs in an adsorbate molecule which then interacts with the ground state catalyst substrate, the process is referred to as a catalyzed photoreaction. When the initial photoexcitation takes place in the catalyst substrate and the photoexcited catalyst then transfers electrons or energy into a ground state molecule, the process is referred to as a sensitized photoreaction. In photogenerated catalysis, the photocatalytic activity (PCA) depends on the ability of the catalyst to create electron-hole pair which generates free radicals (e.g., hydroxyl radicals: $\mathrm{OH}^{*}$ ) able to undergo secondary reactions [9].

The electron-hole pairs can also react with each other and therefore recombine. The recombination process is undesirable for photocatalysis because of the absence of charge carriers which should instead react with substrate molecules effecting photocatalysis. $\mathrm{TiO}_{2}$ has a band gap of $3.2 \mathrm{eV}$ permitting light in the wavelength range between 200 and $390 \mathrm{~nm}$ to excite valence band electrons [10]. For photocatalysis, either artificial light or ultraviolet (UV-A) radiation from the sun can be used. This however represents only about $3 \%$ of sunlight and thus a limitation for processes solely dependent on UV light. The photocatalytic activity can be influenced by doping (also called impregnation). By addition of p-or n-type dopants, it is expected that intrabandgap states are formed thereby decreasing the band gap from $3.2 \mathrm{eV}$ and thus producing a bathochromic shift in the absorption spectrum of $\mathrm{TiO}_{2}$. When metallic ion traps the photogenerated electrons, the half-filled electronic configuration gets disturbed and its stability decreases [11]. The trapped electrons can easily be transferred to an oxygen atom adsorbed on the surface of the catalyst, and the metallic ion can return to its original stable state, half-filled electronic structure [11]. Nonmetal dopants include carbon, sulfur, and nitrogen, [12-14]. Metal dopants are for example gold, platinum, silver, iron, and vanadium [15-19]. The metals are defined as small particles deposited on the catalyst [20]. The effectiveness and photocatalytic activity of the coatings were studied by degradation experiments of MB dye under UV light illumination. MB was used as model dye because of its heteroatomic chemical nature consisting of $\mathrm{C}, \mathrm{H}, \mathrm{N}$, and $\mathrm{S}$. Moreover, $\mathrm{MB}$ is widely used as colorants, and there is a change in colour when it degrades over time.

1.1. Degradation and Mineralization of MB Dye. Houas et al. [21] report the degradation pathway of MB (Figure 1) as follows.

(i) $\mathrm{MB}$ degradation begins with cleavage of $\mathrm{C}-\mathrm{S}^{+}=\mathrm{C}$ functional group via a columbic interaction between $\mathrm{C}-\mathrm{S}^{+}=\mathrm{C}$ functional group and basic $\mathrm{TiO}_{2}[22]$.

(ii) Opening of the central aromatic ring containing both heteroatoms, $\mathrm{S}$ and $\mathrm{N}$. The origin of $\mathrm{H}$ atoms necessary to $\mathrm{C}-\mathrm{H}$ and $\mathrm{N}-\mathrm{H}$ bond formation can be gained from the proton reduction by photogenerated electrons $[23,24]$.

(iii) Formation of a sulfoxide, a sulfone and a sulfonic group as observed in Fenamiphos degradation [22].

(iv) The sulfoxide group can undergo a second attack by an $\mathrm{OH}^{*}$ radical producing the sulfone (nondetected) and causing the definitive dissociation of the two benzenic rings. The sulfone can be attacked by $\mathrm{OH}^{\circ}$ giving sulfonic acid.

(v) Radical $\mathrm{R}-\mathrm{C}_{6} \mathrm{H}_{4}{ }^{\circ}$ can subsequently react with $\mathrm{OH}^{\circ}$ giving phenolic compounds [23].

(vi) Progressive degradation by $\mathrm{OH}^{*}$ attacking dimethylphenyl-amino groups, aldehydes which decarboxylates into $\mathrm{CO}_{2}$.

Conclusively, the degradation leads to the conversion of organic carbon into harmless gaseous $\mathrm{CO}_{2}$ and that of nitrogen and sulfur heteroatoms into inorganic ions, such as nitrate and ammonium and sulfate ions, respectively [21].

\section{Experimental}

2.1. Photocatalytic Experiments. The reaction setup consisted of $\mathrm{TiO}_{2}$ coatings on sintered glass $(150-250 \mu \mathrm{m}$ nominal pore size), packed in a borosilicate tube $26 \mathrm{~cm}$ long and $1 \mathrm{~cm}$ in diameter. Glass particle grain size was between 200 and $400 \mu \mathrm{m}$.

The photocatalytic activity of the coatings was tested by the photooxidation of methylene blue in water with a starting concentration of $14 \mathrm{mg} / \mathrm{L}$ in $200 \mathrm{~mL}$ as feed volume. The tube was placed between two planar dielectric barrier discharge lamps (Osram Planon) emitting UV light of wavelength around $280-420 \mathrm{~nm}$ (Figures 2 and 3).

Methylene blue solution was pumped through the reactor using roller pumps in a continuous manner with a flow rate 
<smiles>CN(C)c1ccc2nc3ccc(N(C)C)cc3[s+]c2c1</smiles>

Figure 1: The chemical structure of methylene blue (drawn with Symyx Draw).

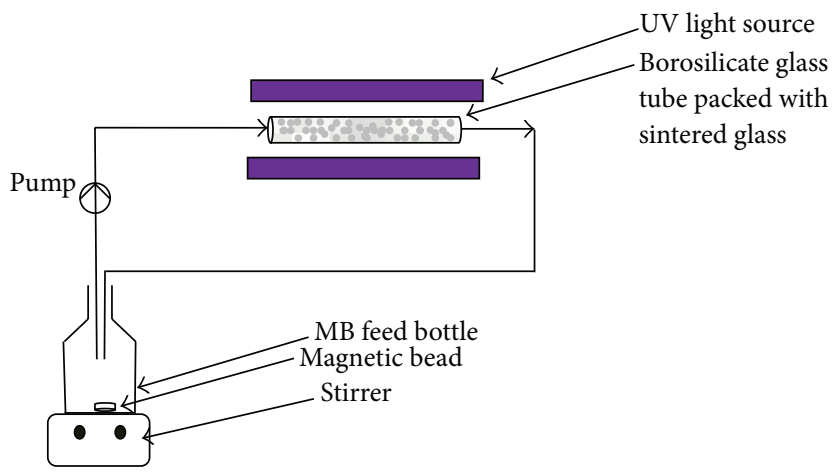

FIGURE 2: Experimental setup for the photocatalytic degradation of MB.

of $15 \mathrm{~mL} / \mathrm{min}$. Samples were collected at intervals up till a period of $4 \mathrm{~h}$ reaction time. Reactions were carried out at room temperature. Blank experiments were performed in the absence of UV light illumination as well as with uncoated sintered glass plates. The concentration of methylene blue in the reaction mixture was measured at regular intervals by measuring the absorbance of an aliquot solution. This was done using a UV-visible (Thermo-Scientific Genesys 10S) spectrophotometer (at $665 \mathrm{~nm}$ ) with deionized water as reference. A Beer-Lambert diagram was established to correlate the absorbance at $665 \mathrm{~nm}$ to $\mathrm{MB}$ concentration. The percentage degradation was calculated as follows:

$$
\text { Degradation }(\%)=\left(\frac{C-C_{0}}{C_{0}}\right) \times 100
$$

$C_{0}$ is the initial concentration of lignin and $C$ is the concentration of methylene blue after photoirradiation. The photocatalytic decomposition of the organic molecules follows the Langmuir-Hinshelwood kinetics, which may be represented as $[21,25]$

$$
\frac{-d C}{d t}=-k C C_{\mathrm{OH}^{*}}
$$

$C$ is the concentration of methylene blue and $C_{\mathrm{OH}} \cdot$ the hydroxyl radical concentration. By the pseudostationary hypothesis (i.e., the $C_{\mathrm{OH}} \cdot$ can be considered to be constant because of the continuous hydroxyl ion generation by photocatalysis) the rate depends only on the methylene blue concentration [26]. The rate expression can be written as follows:

$$
-\ln \left(\frac{C}{C_{0}}\right)=k t
$$

The linear plot of $\ln \left(C / C_{0}\right)$ versus $t$ gives the rate constant, $k$ (slope).

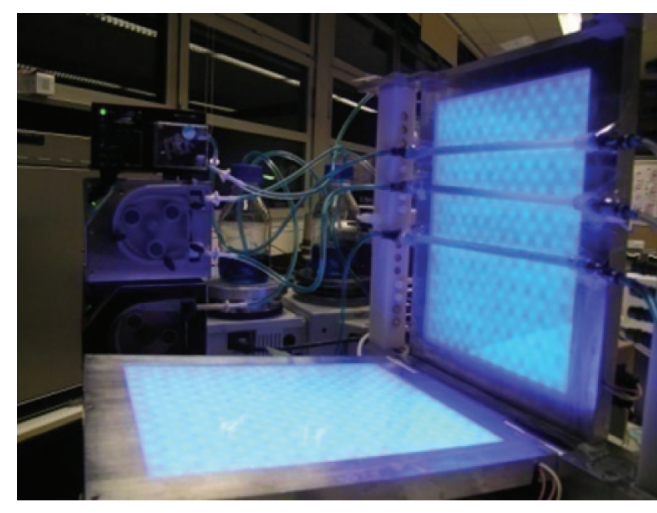

FIgURE 3: Photocatalytic reactor.

2.2. Material and Method. $\mathrm{ZnO}\left(5 \mathrm{~m}^{2} / \mathrm{g}\right)$ was purchased from Sigma Aldrich-Germany, titanium (IV) oxide sulfate dehydrate (titanyloxyssulfate) was purchased from Alfa Aesar. Titanium tetraisopropoxide (TTIP), chloroplatinic acid hydrate (99.999\%), polyethylene glycol (average Mn 300) were purchased from Aldrich. Aeroxide $\mathrm{TiO}_{2}$ P25 (surface area $50 \mathrm{~m}^{2} / \mathrm{g}$ and average particle size $30 \mathrm{~nm}$ ) was obtained from Evonik and consisted of $70 \%$ anatas and $30 \%$ rutil. Methylene blue, tetraethylortosilicate (TEOS) and ammonium monovanadate were purchased from Merck. Borosilicate glass tubes containing sintered glass particles were obtained from ROBU-Germany. All chemicals were used as received.

2.2.1. Preparation of TEOS Solution. Tetraethylorthosilicate (TEOS) sol was prepared by adding dropwise $77 \mathrm{~mL}$ of 2propanol mixed with $5 \mathrm{~mL}$ of $\mathrm{H}_{2} \mathrm{O}$ and $4 \mathrm{~mL}$ of $\mathrm{HNO}_{3}$ to $22 \mathrm{~mL}$ TEOS at room temperature. The resultant solution was stirred for $2 \mathrm{~h}$.

2.2.2. Preparation of $\mathrm{TiOSO}_{4} 30,6 w t \%$ Gel. In a $200 \mathrm{~mL}$ beaker 45,9 g of $\mathrm{TiOSO}_{4}$ (Alfa Aesar) was weighed and $104,1 \mathrm{~mL}$ of water was added. The suspension was stirred till a clear solution was obtained. The solution was heated up to $85^{\circ} \mathrm{C}$ while adding $5 \mathrm{~N} \mathrm{NaOH}$ dropwise until a $\mathrm{pH}$ of 5,5 was reached. The temperature was maintained for $8 \mathrm{~h}$ under stirring. After that, the gel was washed 3 times with $75 \mathrm{~mL}$ water each time. The gel was resuspended in distilled water using $150 \mathrm{~mL}$ of water and then sonicated for $6 \mathrm{~h}$. After sonication the gel was ready for coating.

2.2.3. Preparation of $\mathrm{TiO}_{2}-\mathrm{P} 25$ Suspension. $\mathrm{TiO}_{2}-\mathrm{P} 25$ (Aeroxide, $\mathrm{TiO}_{2}$, Evonik Industries) suspensions were prepared by adding $8,75 \mathrm{~g} \mathrm{TiO}_{2}-\mathrm{P} 25$ to $50 \mathrm{~mL}$ water and sonicated for $60 \mathrm{~min}$. Tetraethylorthosilicate (TEOS) layers were applied on the glass substrate before coating with $\mathrm{TiO}_{2}-\mathrm{P} 25$.

2.2.4. Preparation of $\mathrm{ZnO}$ Suspension. $12 \mathrm{~g}$ of $\mathrm{ZnO}$ was added to $150 \mathrm{~mL}$ of water and stirred for $1 \mathrm{~h}$. In a separate beaker, nitric acid (65\%) was added dropwise to $60 \mathrm{~mL}$ TEOS solution till a $\mathrm{pH}$ 1,55 was reached. $\mathrm{ZnO}$ suspension was then mixed with TEOS by adding dropwise TEOS to $\mathrm{ZnO}$ suspension and stirred for $2 \mathrm{~h}$ at room temperature. 
2.2.5. Preparation of $\mathrm{ZnO}+\mathrm{TiO}_{2}-\mathrm{P} 25-\mathrm{SiO}_{2}$ Suspension. $\mathrm{TiO}_{2}-$ $\mathrm{P} 25$ suspension was prepared by adding $5,25 \mathrm{~g} \mathrm{TiO}_{2}-\mathrm{P} 25$ in $30 \mathrm{~mL}$ water and sonicated for $60 \mathrm{~min}$. From the previously prepared $\mathrm{ZnO} / \mathrm{TEOS}$ suspension, $20 \mathrm{~mL}$ was added to $\mathrm{TiO}_{2}$ P25 suspension and left to mix for $2 \mathrm{~h}$ at room temperature.

2.2.6. Preparation of $\mathrm{TiOSO}_{4}-30,6 w t \%+P E G$ Gel. In a beaker, 7,4 $\mathrm{g}$ of PEG-300, 45,9 $\mathrm{g}$ of $\mathrm{TiOSO}_{4}$, and $104,1 \mathrm{~mL}$ of water were mixed together. The suspension was stirred till a clear solution was obtained. The solution was heated up to $85^{\circ} \mathrm{C}$ while adding $5 \mathrm{~N} \mathrm{NaOH}$ dropwise until a $\mathrm{pH}$ of 5,5 was reached. The temperature was maintained for $8 \mathrm{~h}$ under continual stirring. Following that, the gel was washed 3 times with $75 \mathrm{~mL}$ water each time. The gel was resuspended in distilled water using $150 \mathrm{~mL}$ of water and then sonicated for $6 \mathrm{~h}$. After sonication, the gel was ready for coatings.

2.2.7. Preparation of $\mathrm{TiO}_{2}-\mathrm{P} 25-\mathrm{SiO}_{2}+\mathrm{Pt}$, $\mathrm{TiOSO}_{4}-30,6 w t \%+$ $\mathrm{NH}_{3}, \mathrm{TiOSO}_{4}-30,6 w t \%+\mathrm{NH}_{4} \mathrm{VO}_{3}, \mathrm{TiOSO}_{4} 30,6 w t \%+\mathrm{NH}_{3}$, and TTIP+Pt Gels. The amount of dopant used was $1 \mathrm{wt} \%$ relative to $\mathrm{TiO}_{2}$ concentration in the gel or suspension in question. The metal precursor was directly added to the gel and then stirred for $30 \mathrm{~min}$ prior to coating. For example, $86 \mathrm{mg}$ of $\mathrm{NH}_{4} \mathrm{VO}_{3}$ was added in a $75 \mathrm{~mL} \mathrm{TiO} 2$ gel derived from $\mathrm{TiOSO}_{4-} 30,6 \mathrm{wt} \%$.

2.2.8. Preparation of $\mathrm{TiOSO}_{4}-30,6 w t \%+\mathrm{TiO}_{2}-\mathrm{P} 25$ Suspension. $\mathrm{TiO}_{2}-\mathrm{P} 25$ suspensions was prepared by dissolving $3,5 \mathrm{~g} \mathrm{TiO}_{2}$ $\mathrm{P} 25$ in $20 \mathrm{~mL}$ water and sonicated for $60 \mathrm{~min}$. To this suspension $30 \mathrm{~mL}$ of $\mathrm{TiOSO}_{4}-30,6 \mathrm{wt} \%$ gel was added and sonicated for $1 \mathrm{~h}$ at $25^{\circ} \mathrm{C}$.

2.2.9. Preparation of TTIP Gel. $\mathrm{TiO}_{2}$ gel was prepared by mixing $36 \mathrm{~mL}$ of titanium tetraisopropoxide (TTIP), $400 \mathrm{~mL}$ of $\mathrm{H}_{2} \mathrm{O}$, and $3.8 \mathrm{~mL}$ of $\mathrm{HNO}_{3}(65 \% \mathrm{w} / \mathrm{w})$. The mixture was stirred for $24 \mathrm{~h}$ at room temperature $\left(25^{\circ} \mathrm{C}\right)$ and then left to stand for $6 \mathrm{~h}$ (ageing time).

2.2.10. Coating Procedure of TEOS on Glass. TEOS was pumped through both sides of the glass tube and then left to dry at $150^{\circ} \mathrm{C}$. The oven temperature was then raised to $300^{\circ} \mathrm{C}$ and maintained for $3 \mathrm{~h}$. Coating with $\mathrm{TiO}_{2}-\mathrm{P} 25$ then followed.

2.2.11. Coating Procedure of Gels and Suspensions on Glass. The gel was pumped with use of a roller pump through each side of the glass tubes to ensure a homogeneous coating. This was done for each time for $3 \mathrm{~min}$ with the pumping rate set at $10 \mathrm{~mL} / \mathrm{min}$. After coating, the tubes were placed in an oven and heating rate was set at $5^{\circ} \mathrm{C} / \mathrm{min}$. When the oven attained $110^{\circ} \mathrm{C}$, the tubes were left to dry for $2 \mathrm{~h}$. In order to carry out the calcinations step, the oven temperature was raised to $500^{\circ} \mathrm{C}$ with heating rate still maintained at $5^{\circ} \mathrm{C} / \mathrm{min}$. The oven temperature was maintained at $500^{\circ} \mathrm{C}$ for $1 \mathrm{~h}$. After the oven had cooled down, the tubes were removed from the oven and were now ready for photocatalytic experiments.

\section{Results and Discussion}

3.1. Morphology of Coating. Scanning electron microscopy (SEM) was the primary tool for characterizing the surface morphology and fundamental physical properties of the material surface such as porosity, shape, and appropriate size distribution of coating. Samples consisted of sintered glass plates cut to a size of $1 \mathrm{~cm}^{2}$ dipped into the gel or suspension. Drying and calcination were done the same as was the case with borosilicate glass tubes. The micrographs for the uncoated sintered glass, Figures 4(a) and 4(b), show structures formed by glass particles of approx. 200-400 $\mu \mathrm{m}$ in size sintered together. Figures 4(c)-4(f) show micrographs of the coated glass material. It can be observed that the form and structure of the coating are considerably well distributed all over the surface of the sintered glass. Figures $4(\mathrm{e})$ and $4(\mathrm{f})$ consist of a double coating whereby TEOS is first coated and $\mathrm{TiO}_{2}-\mathrm{P} 25$ follows. Figure 4(f) shows a micrograph with higher resolution and the thickness of the coating can be seen. Some fissures are also observed at joints between sintered particles and on the glass particles as a result of drying. It is worthwhile noting that these micrographs originate from sintered glass plates whereby the drying mechanism could be harsher as heat radiations directly strike on them as compared to a borosilicate glass tube encaging the sintered glass particles.

3.2. Degradation Experiments. UV-Vis spectroscopy was applied to monitor MB degradation. Absorption maxima appear at wavelength $291 \mathrm{~nm}$ and $665 \mathrm{~nm}$. An example of such a spectrum is represented in Figure 5. The coating consisted of $\mathrm{TiOSO}_{4-3} 30,6 \mathrm{wt} \%$ under photocatalysis of $\mathrm{MB}$ for a period of $4 \mathrm{~h}$. The samples were collected at intervals: $(-60,-15,0,30$, $60,90,120,150,180)$ min. Minus (-) 60 and -15 min samples were collected $60 \mathrm{~min}$ and $15 \mathrm{~min}$, respectively, before putting on UV illumination. $(\times 2)$ describes the dilution coefficient in order that peaks fit in range of the absorption spectrum. Maximum absorption in the visible range at $665 \mathrm{~nm}$ was selected to follow MB degradation.

Figure 6 shows an absorbance-time diagram of MB. The reaction was performed in the dark with uncoated sintered glass. No significant adsorption is noted. With the presence of $\mathrm{TiO}_{2}$ coating, one notes a very strong adsorption till approx. $60 \mathrm{~min}$ suggesting adsorption equilibrium is attained after $60 \mathrm{~min}$ recirculation in the dark (Figure 7). For all experiments, $\mathrm{MB}$ was hence recirculated through the reactor for $60 \mathrm{~min}$ before UV light was put on. The adsorption mechanism is a result of columbic interaction between $\mathrm{MB}$ which has a cationic configuration and $\mathrm{OH}^{-}$ ions present on the surface of $\mathrm{TiO}_{2}$ nanocrystallites [21]. The time dependent UV-Vis absorption spectra of aqueous $\mathrm{MB}$ show a decrease in absorbance for peaks at $665 \mathrm{~nm}$ and $291 \mathrm{~nm}$ as $\mathrm{MB}$ blue degrades (Figure 5). A shoulder at around $665 \mathrm{~nm}$ was observed. Other peak formation was noted at wavelengths $220 \mathrm{~nm}$ and $240 \mathrm{~nm}$. This suggested the formation of intermediate products. Absorbance for both the intermediate peak and parent $\mathrm{MB}$ peak reduced with time and after $3 \mathrm{~h}$ no peaks were observed indicating destruction of $\mathrm{MB}$ dye and intermediate products. 


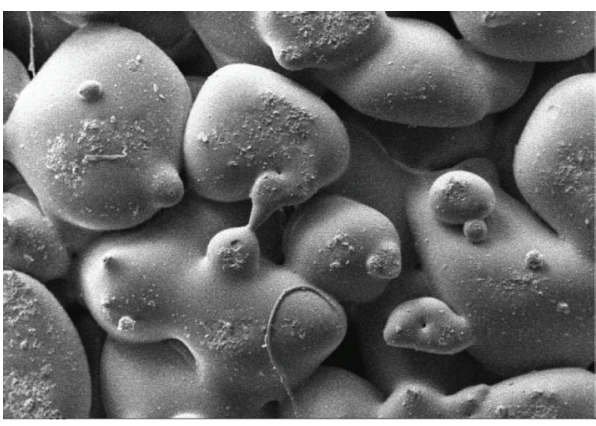

$$
\stackrel{\longmapsto}{200 \mu \mathrm{m}}
$$

(a)

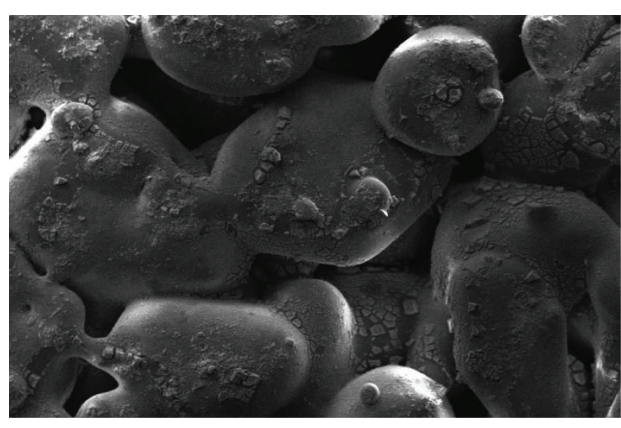

$$
\stackrel{\longmapsto}{\stackrel{1}{\longrightarrow}}
$$

(c)

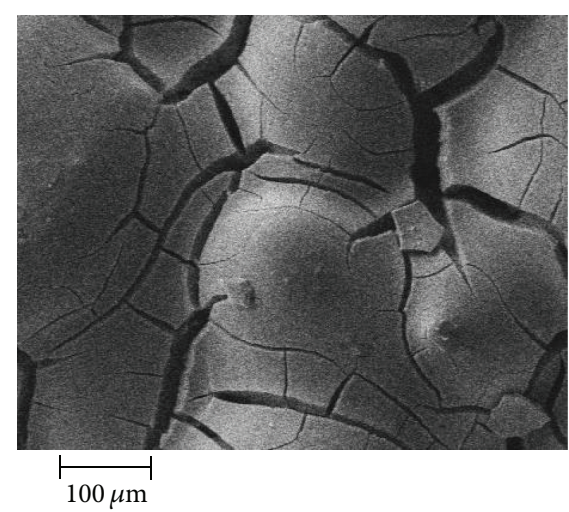

(e)

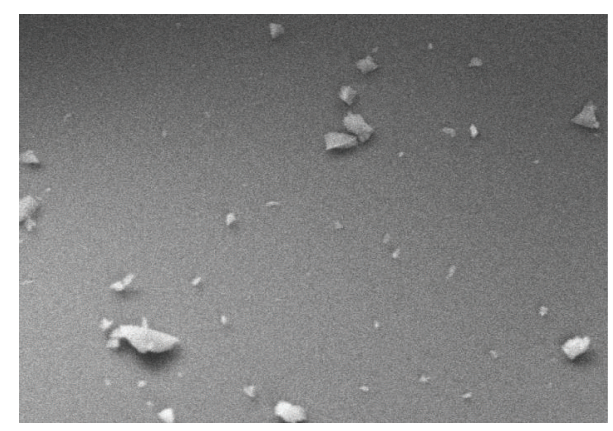

$$
\stackrel{\longmapsto}{10 \mu \mathrm{m}}
$$

(b)

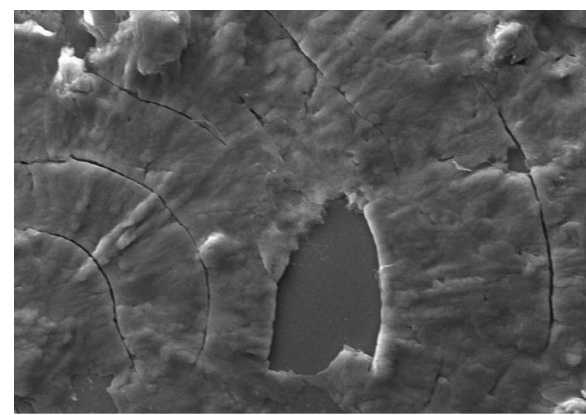

$$
\stackrel{\longmapsto}{10 \mu \mathrm{m}}
$$

(d)

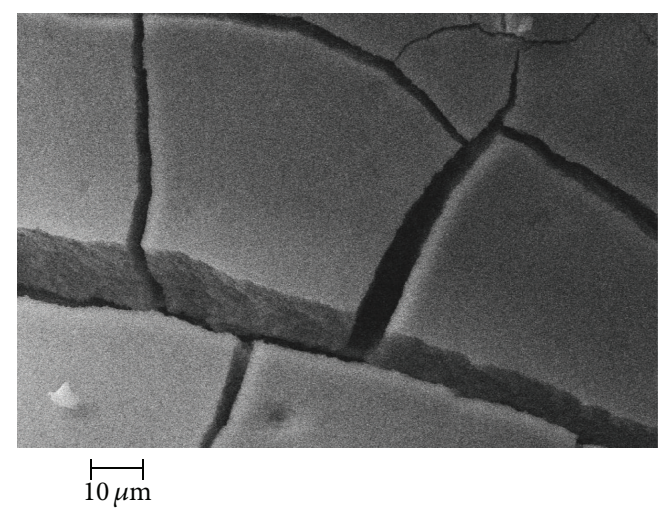

(f)

FIGURE 4: SEM images for uncoated borosilicate sintered glass ((a) and (b)), $\mathrm{TiO}_{2}\left(\mathrm{TiOSO}_{4}-30,6\right.$ wt $\left.\%\right)$ coating on borosilicate glass ((c) and (d)), (e) $\mathrm{TiO}_{2}-\mathrm{P} 25-\mathrm{SiO}_{2}$, (f) $\mathrm{TiO}_{2}-\mathrm{P} 25-\mathrm{SiO}_{2}$.

Decolorization of $\mathrm{MB}$ solution was observed during the photocatalytic degradation experiments. Figure 8 depicts the decolorization pattern obtained with $\mathrm{TiOSO}_{4-} 30,6 \mathrm{wt} \%+$ $\mathrm{TiO}_{2}-\mathrm{P} 25$ catalyst over time. From left to rights, samples were collected after $-60,-15,0,30,60,90,120,180 \mathrm{~min}$.

Figure 9 shows the change in $\mathrm{MB}$ concentration in the recirculating reactor, while Figure 10 shows the plot of $\ln \left(C / C_{0}\right)$ versus $t$ for rate constant determination. A decrease in $\mathrm{MB}$ concentration in the presence of UV light is observed for all catalytic systems. However in the absence of UV light with coated glass material, a slight change in concentration close to $20 \%$ attributed to adsorption effects was observed. UV light brought along the source of photons needed by the catalyst for electron excitation and hence reaction. Once the photons intercept with the catalyst, they absorb light generating surface trapped electron hole pairs, which undergo the interfacial processes of oxygen reduction and methylene blue oxidation.

$\mathrm{TiO}_{2}-\mathrm{P} 25+\mathrm{SiO}_{2}, \quad \mathrm{TiO}_{2}-\mathrm{P} 25+\mathrm{SiO}_{2}+\mathrm{Pt}$, and $\mathrm{TiOSO}_{4-}$ $30 \mathrm{wt} \%$ showed highest degradation rates close to $100 \%$ after 90 min illumination with degradation rates exceeding $50 \%$ after 30 minutes. TTIP $+\mathrm{Pt}$ and TTIP showed lowest degradation rates (Figure 11). $\mathrm{TiOSO}_{4}-30,6 \mathrm{wt} \%$ showed highest reaction rate of $0,0313 \mathrm{~min}^{-1}$ followed by $\mathrm{TiO}_{2}$ $\mathrm{P} 25+\mathrm{SiO}_{2}+\mathrm{Pt}, \quad \mathrm{TiO}_{2}-\mathrm{P} 25+\mathrm{SiO}_{2}$, and $\mathrm{TiOSO}_{4}+\mathrm{TiO}_{2}-\mathrm{P} 25$ 


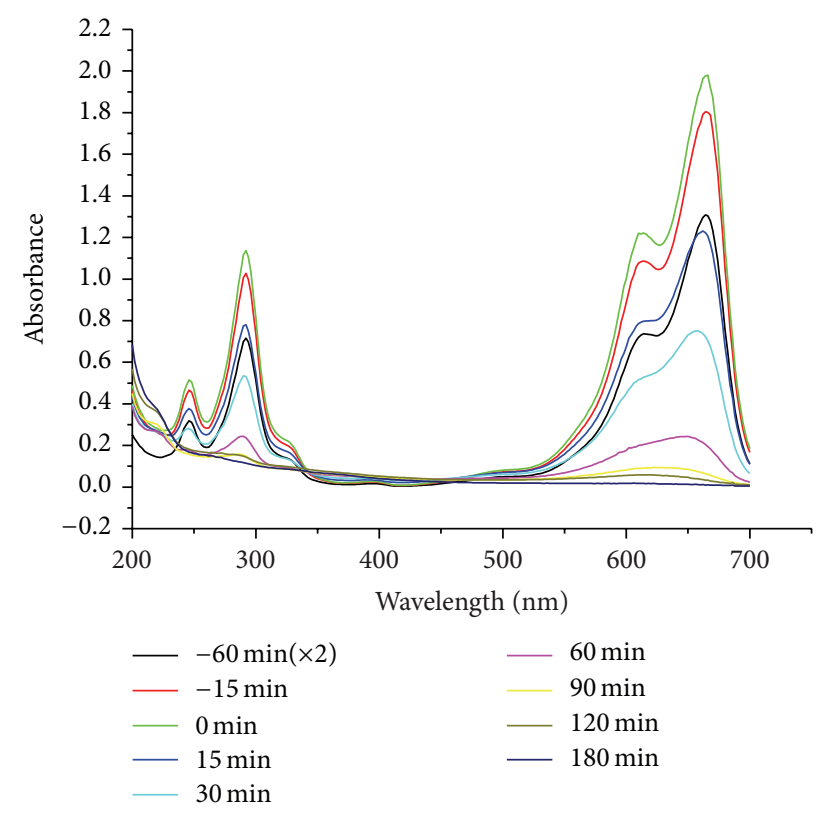

FIgURE 5: Typical time dependent UV-Vis absorption spectra of aqueous MB solution irradiated with UV light $(280-420 \mathrm{~nm})$ for different time intervals. The spectrum is obtained for sol-gel derived $\mathrm{TiO}_{2}$ from titanyloxysulphate.

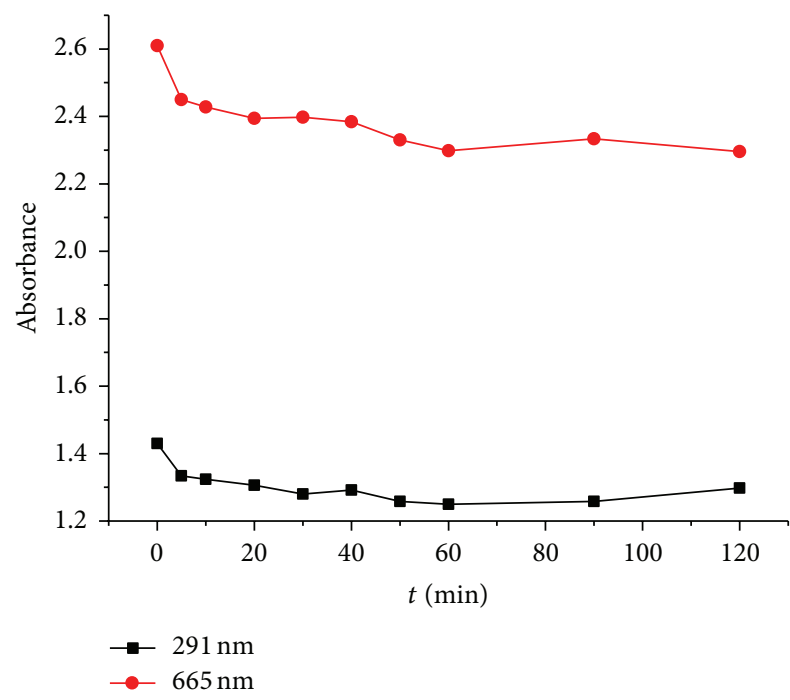

FIgURE 6: Absorption-time diagram, uncoated glass and no lights.

showing reaction rates of $0,0263 \mathrm{~min}^{-1}, 0,0215 \mathrm{~min}^{-1}$, and $0,0210 \mathrm{~min}^{-1}$, respectively (Figure 12 ).

The aim of combining catalysts was to achieve optimum catalytic activity by increasing total active surface area and hence the availability of more active sites on catalyst surface. $\mathrm{TiO}_{2}-\mathrm{P} 25$ was made to bind on the glass substrate by the aid of TEOS. $\mathrm{SiO}_{2}$ which comprises TEOS has been widely applied as catalytic support materials due to its versatile properties and tunable parameters (e.g., pore size and specific surface area (SSA)) and hence could also have played the role of stabilizing the coating as a binding system [27]. Moreover, because

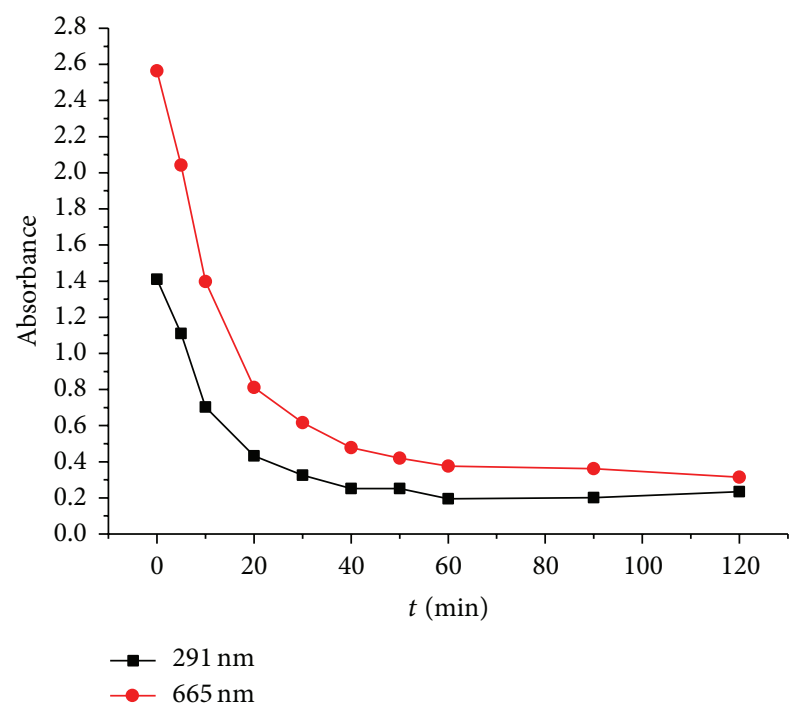

FIGURE 7: Absorption-time diagram, coated glass and no lights.

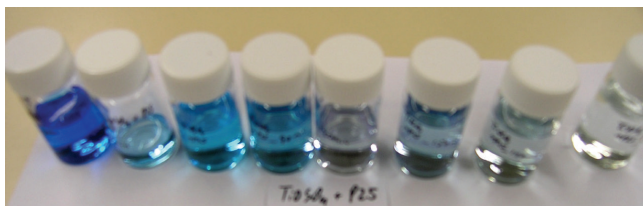

Figure 8: $\mathrm{MB}$ decolorization with $\mathrm{TiOSO}_{4} 30,6 \mathrm{wt} \%+\mathrm{TiO}_{2}-\mathrm{P} 25$ catalyst.

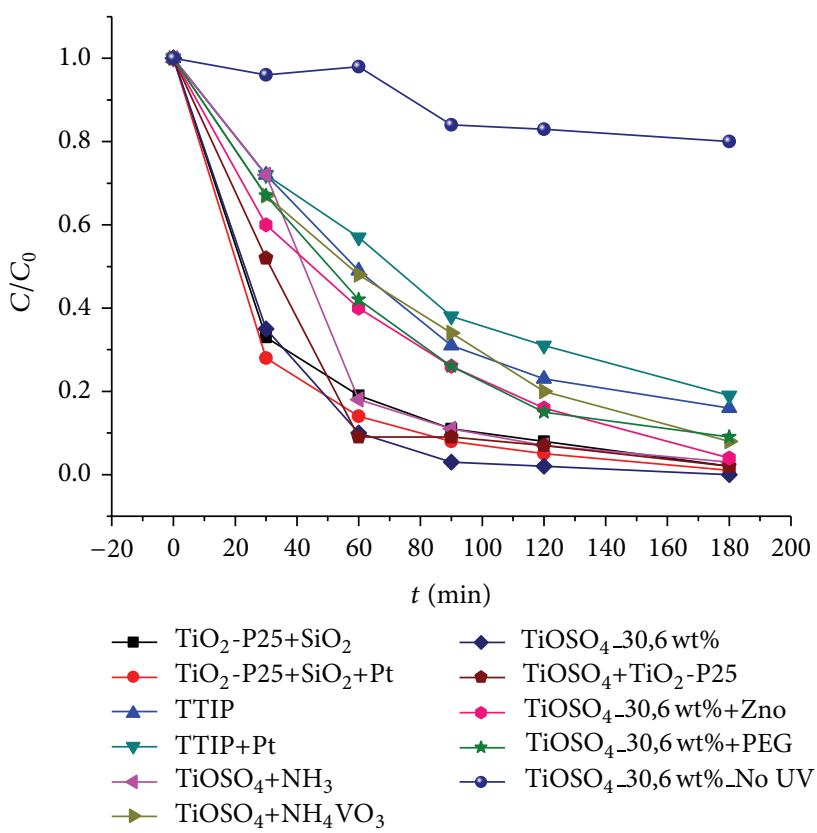

Figure 9: Change in concentration of $\mathrm{MB}$ with time. $\mathrm{MB}$ initial concentration: $14 \mathrm{mg} / \mathrm{L}$, UV radiation $\lambda>280 \mathrm{~nm}-420 \mathrm{~nm}$, recirculating reactor open to air, absorption at $665 \mathrm{~nm}$ and immobilized catalysts. 


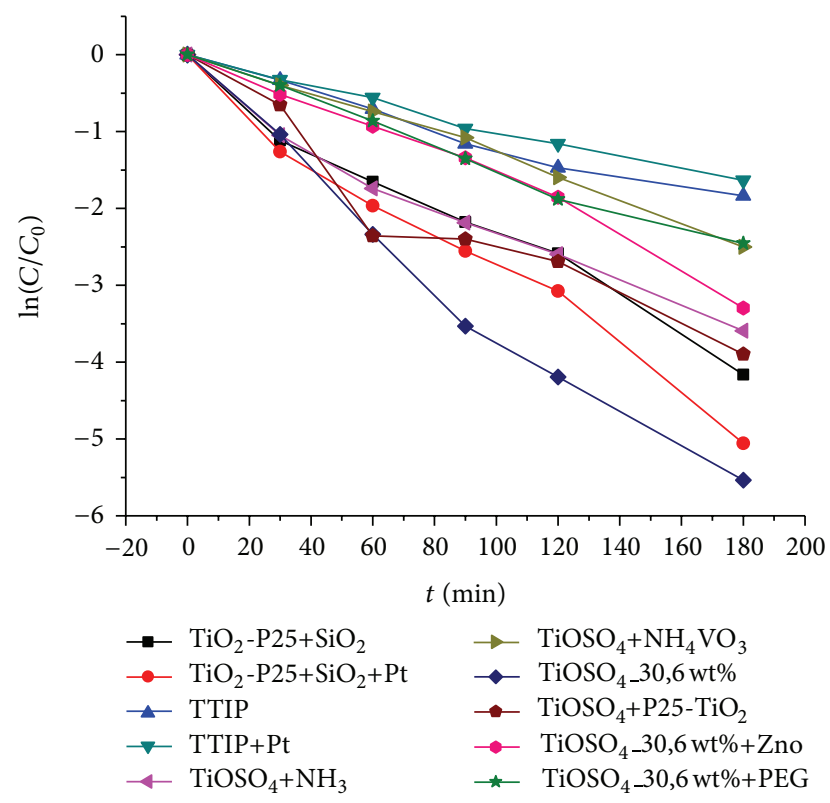

Figure 10: Plot of $\ln \left(C / C_{0}\right)$ versus $t$ for rate constant determination.

TEOS in solution is colorless and while coated it remains colorless, it therefore had no adverse effect on the turbidity of the reaction or transparency of the coatings. This transparent nature assures the photon flux to be easily intercepted by the catalyst. On the contrary case, there would be a decrease in penetration of UV light and hence the photoactivated volume of the reactant solution decreases [28]. TEOS could also have an adverse effect in compromising the viscosity of the gel, morphology and crystalline nature of catalyst on glass, and composition of catalyst to be impregnated.

Nitrogen addition as dopant so as to mitigate intrabandgap states [11] was tested by the addition of $\mathrm{NH}_{3}$ and $\mathrm{NH}_{4} \mathrm{VO}_{3}$ to $\mathrm{TiOSO}_{4}$ as catalyst precursor. Reaction rates achieved for $\mathrm{NH}_{3}$ and $\mathrm{NH}_{4} \mathrm{VO}_{3}$ were $0,0184 \mathrm{~min}^{-1}$ and $0,0133 \mathrm{~min}^{-1}$ making a difference of $39 \%$ which was far still lower than that obtained by using unmodified $\mathrm{TiOSO}_{4}$. The reaction rate of $\mathrm{TiOSO}_{4-3} 30,6 \mathrm{wt} \%{ }_{-} \mathrm{NH}_{3}$ was $70 \%$ lower than that of $\mathrm{TiOSO}_{4} 30,6 \mathrm{wt} \%$. The adverse results obtained by $\mathrm{N}_{2}$ addition can be because total active surface area on catalyst reduces with excess $\mathrm{N}_{2}$ addition and hence availability of less active sites on catalyst surface [29]. Addition of PEG (polyethylene glycol), $\mathrm{ZnO}, \mathrm{NH}_{3}$, and $\mathrm{NH}_{4} \mathrm{VO}_{3}$ to the catalytic system all gave degradation rates greater than $50 \%$ after $60 \mathrm{~min}$ of reaction. After $90 \mathrm{~min}$ reaction time degradation rates reached were in the order $\mathrm{TiOSO}_{4-30,6} \mathrm{wt} \%>$ $\mathrm{TiO}_{2}-\mathrm{P} 25+\mathrm{SiO}_{2}+\mathrm{Pt} \approx \mathrm{TiOSO}_{4-} 30,6 \mathrm{wt} \%+\mathrm{TiO}_{2}-\mathrm{P} 25>\mathrm{TiO}_{2}-$ $\mathrm{P} 25+\mathrm{SiO}_{2}>\mathrm{TiOSO}_{4}-30,6 \mathrm{wt} \%+\mathrm{NH}_{3} \approx \mathrm{TiOSO}_{4-3} 30,6 \mathrm{wt} \%+$ $\mathrm{NH}_{4} \mathrm{VO}_{3}>\mathrm{ZnO}+\mathrm{TiOSO}_{4}-30,6$ wt $\% \approx \mathrm{TiOSO}_{4}+\mathrm{PEG}>$ TTIP > TTIP+Pt. Degradation values were 97\%, 92\%, 91\%, $89 \%, 82 \%, 80 \%, 74 \%, 74 \%, 69 \%$, and $62 \%$, respectively. Use of PEG was to prevent the aggregation of titania particles in the gel [30]. Adding $\mathrm{Pt}$ to $\mathrm{TiO}_{2}-\mathrm{P} 25+\mathrm{SiO}_{2}$ system brought about a corresponding increase in reaction rate close to $10 \%$ probably because of the formation of intrabandgaps and thus curbing electron-hole pair recombination.

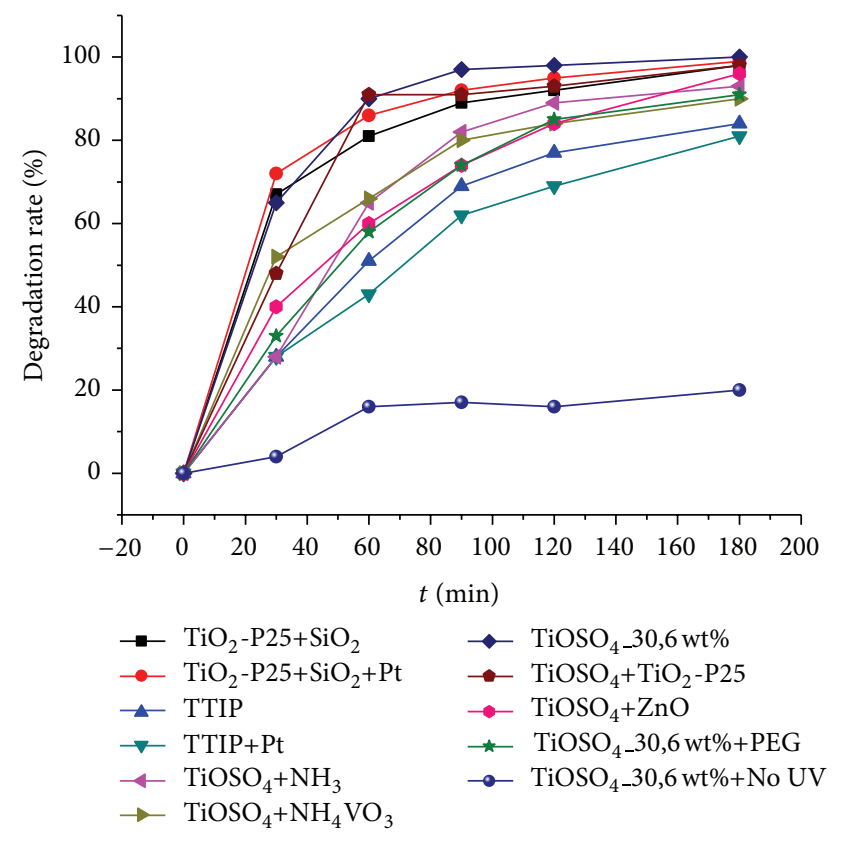

FIGURE 11: Degradation kinetic of MB using diverse immobilized catalyst under UV light. MB initial concentration: $14 \mathrm{mg} / \mathrm{L}, \mathrm{UV}$ radiation $\lambda>280 \mathrm{~nm}-420 \mathrm{~nm}$, recirculating reactor open to air, absorption at $665 \mathrm{~nm}$ and immobilized catalysts.

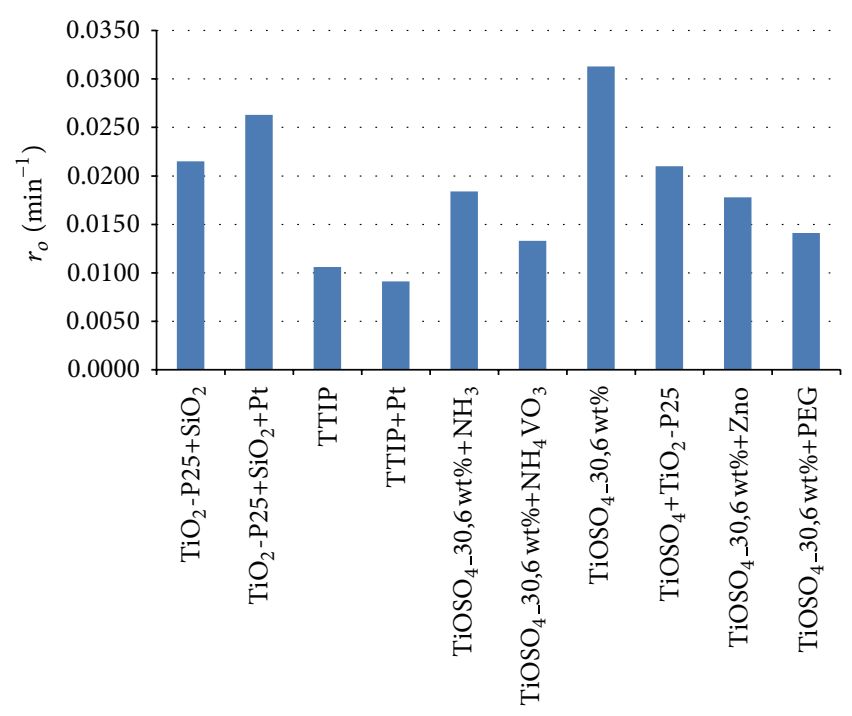

FIGURE 12: Reaction rates of the photocatalytic degradation of MB $(14 \mathrm{mg} / \mathrm{L})$ under UV light on immobilized catalysts.

\section{Conclusion}

This work presents a comparative study of coatings produced via sol-gel basis on sintered glass particles in a borosilicate glass tube. The following catalytic systems were synthesized: $\mathrm{TiO}_{2}-\mathrm{P} 25+\mathrm{SiO}_{2}, \mathrm{TiO}_{2}-\mathrm{P} 25+\mathrm{SiO}_{2}+\mathrm{Pt}$, TTIP, TTIP $+\mathrm{Pt}$, $\mathrm{TiOSO}_{4}+\mathrm{PEG}, \mathrm{TiOSO}_{4} 30,6 \mathrm{wt} \%, \mathrm{TiOSO}_{4}-30,6 \mathrm{wt} \%+\mathrm{NH}_{3}$, $\mathrm{TiOSO}_{4}-30,6 \mathrm{wt} \%+\mathrm{NH}_{4} \mathrm{VO}_{3}, \mathrm{TiOSO}_{4}-30,6 w \mathrm{t} \%+\mathrm{TiO}_{2}-\mathrm{P} 25$, and $\mathrm{ZnO}+\mathrm{TiOSO}_{4-3} 30,6 \mathrm{wt} \%$. The advantage of sol-gel in catalyst preparation was exploited to combine catalyst to 
act as cocatalyst. Commercial obtainable $\mathrm{TiO}_{2}-\mathrm{P} 25$ widely applied in suspension systems was effectively immobilized on sintered glass support with the aid of tetraethylorthosilicate (TEOS) solution which acted as support material. The catalytic films had very good adherence on the sintered glass and the films retained a constant efficiency when reused after washing with water. The coatings were considerably well distributed all over the surface of the sintered glass. This is very promising for their potential use as immobilized catalyst in batch or flow reactor [31].

The reactor design consisting of sintered glass with pore size between 150 and $250 \mu \mathrm{m}$ and glass particle grain size between 200 and $400 \mu \mathrm{m}$ packed in a borosilicate tube placed between two planar dielectric barrier discharge lamps (osram planon) is reported for the first time. The advantages of the reactor design are as follows: a constant plug flow and therefore a narrow residence time distribution and good mixing condition with the sintered glass acting as static mixer. The broad surface of the light source insures incident light to be well distributed all over the surface of the glass tubes.

A comparative study to access the degradation rate of the different coatings was done with MB. Illumination of uncoated glass material gave negligible changes in $\mathrm{MB}$ degradation after long irradiation time of $3 \mathrm{~h}$. A fast decrease in $\mathrm{MB}$ concentration in the presence of UV light is observed. However, in the absence of UV light with coated glass material, a slight change in concentration close to $20 \%$ attributed to adsorption effects was observed. The effect of adding $\mathrm{Pt}$ as metal ion was monitored with $\mathrm{TiO}_{2}-\mathrm{P} 25$ and TTIP gels. $\mathrm{TiO}_{2}-\mathrm{P} 25+\mathrm{SiO}_{2}, \mathrm{TiO}_{2}-\mathrm{P} 25+\mathrm{SiO}_{2}+\mathrm{Pt}$, and $\mathrm{TiOSO}_{4}-30,6 \mathrm{wt} \%$ coatings showed highest degradation rates close to $100 \%$ after 90 min illumination with degradation rates exceeding $50 \%$ after 30 minutes. TTIP+Pt showed lowest degradation rates. New absorption peaks in the UV spectrum suggested the formation of intermediate products which disappeared in course of reaction indicating destruction of $\mathrm{MB}$ dye and intermediate products $[21,32,33]$.

\section{Acknowledgments}

The authors gratefully thank the Federal Ministry of Education and Research (BMBF) for funding (FKZ17N0310). The authors also thank Robu Filterglas GmbH, Hattert, Fresenius Medical Care Deutschland GmbH, Bad Homburg, and Evonik industries for providing materials used in this work.

\section{References}

[1] P. B. Dejohn and R. A. Hutchins, "Treatment of dye wastes with granular activated carbon," Textile Chemist and Colorist, vol. 8, p. 69, 1976.

[2] Y. M. Slokar and A. Majcen Le Marechal, "Methods of decoloration of textile wastewaters," Dyes and Pigments, vol. 37, no. 4, pp. 335-356, 1998.

[3] S. S. Patll, "Biodegradation studies of aniline and nitrobenzene in aniline plant waste water by gas chromatography," Environmental Science and Technology, vol. 22, no. 10, pp. 1160-1165, 1988.

[4] G. Sagawe, R. J. Brandi, D. Bahnemann, and A. E. Cassano, "Photocatalytic reactors for treating water pollution with solar illumination. I: a simplified analysis for batch reactors," Chemical Engineering Science, vol. 58, no. 12, pp. 2587-2599, 2003.

[5] C. S. Turchi, D. F. Ollis, and R. W. Matthews, "Photocatalytic reactor design: an example of mass-transfer limitations with an immobilized catalyst," Journal of Physical Chemistry, vol. 92, no. 23, pp. 6852-6853, 1988.

[6] M. C. Hidalgo and D. Bahnemann, "Highly photoactive supported $\mathrm{TiO}_{2}$ prepared by thermal hydrolysis of $\mathrm{TiOSO}_{4}$ : optimisation of the method and comparison with other synthetic routes," Applied Catalysis B, vol. 61, no. 3-4, pp. 259-266, 2005.

[7] M. C. Hidalgo, S. Sakthivel, and D. Bahnemann, "Highly photoactive and stable $\mathrm{TiO}_{2}$ coatings on sintered glass," Applied Catalysis A, vol. 277, no. 1-2, pp. 183-189, 2004.

[8] D. Chen and A. K. Ray, "Photodegradation kinetics of 4-nitrophenol in $\mathrm{TiO}_{2}$ suspension," Water Research, vol. 32, no. 11, pp. 3223-3234, 1998.

[9] A. L. Linsebigler, G. Lu, and J. T. Yates Jr., "Photocatalysis on $\mathrm{TiO}_{2}$ surfaces: principles, mechanisms, and selected results," Chemical Reviews, vol. 95, no. 3, pp. 735-758, 1995.

[10] A. F. Hollemann and E. Wiberg, Lehrbuch Der Anorganischen Chemie, De Grutyer, Berlin, Germany, 1995.

[11] R. Subasri, M. Tripathi, K. Murugan, J. Revathi, G. V. N. Rao, and T. N. Rao, "Investigations on the photocatalytic activity of sol-gel derived plain and $\mathrm{Fe}^{3+} / \mathrm{Nb}^{5+}$-doped titania coatings on glass substrates," Materials Chemistry and Physics, vol. 124, no. 1, pp. 63-68, 2010.

[12] S. Sakthivel and H. Kisch, "Daylight photocatalysis by carbonmodified titanium dioxide," Angewandte Chemie, vol. 42, no. 40, pp. 4908-4911, 2003.

[13] T. Umebayashi, T. Yamaki, H. Itoh, and K. Asai, "Band gap narrowing of titanium dioxide by sulfur doping," Applied Physics Letters, vol. 81, no. 3, pp. 454-456, 2002.

[14] R. Nakamura, T. Tanaka, and Y. Nakato, "Mechanism for visible light responses in anodic photocurrents at $\mathrm{N}$-doped $\mathrm{TiO}_{2}$ film electrodes," Journal of Physical Chemistry B, vol. 108, no. 30, pp. 10617-10620, 2004.

[15] M. S. Lee, S.-S. Hong, and M. Mohseni, "Synthesis of photocatalytic nanosized $\mathrm{TiO}_{2}-\mathrm{Ag}$ particles with sol-gel method using reduction agent," Journal of Molecular Catalysis A, vol. 242, no. 1-2, pp. 135-140, 2005.

[16] Y.-S. Ma, C.-N. Chang, Y.-P. Chiang, H.-F. Sung, and A. C. Chao, "Photocatalytic degradation of lignin using $\mathrm{Pt} / \mathrm{TiO}_{2}$ as the catalyst," Chemosphere, vol. 71, no. 5, pp. 998-1004, 2008.

[17] Q. Li, R. Xie, E. A. Mintz, and J. K. Shang, "Enhanced visiblelight photocatalytic degradation of humic acid by palladiummodified nitrogen-doped titanium oxide," Journal of the American Ceramic Society, vol. 90, no. 12, pp. 3863-3868, 2007.

[18] J. O. Carneiro, V. Teixeira, A. Portinha, L. Dupák, A. Magalhães, and P. Coutinho, "Study of the deposition parameters and Fe-dopant effect in the photocatalytic activity of $\mathrm{TiO}_{2}$ films prepared by dc reactive magnetron sputtering," Vacuum, vol. 78, no. 1, pp. 37-46, 2005.

[19] J. C.-S. Wu and C.-H. Chen, "A visible-light response vanadiumdoped titania nanocatalyst by sol-gel method," Journal of Photochemistry and Photobiology A, vol. 163, no. 3, pp. 509-515, 2004.

[20] S. C. Chan and M. A. Barteau, "Preparation of highly uniform $\mathrm{Ag} / \mathrm{TiO}_{2}$ and $\mathrm{Au} / \mathrm{TiO}_{2}$ supported nanoparticle catalysts by photodeposition," Langmuir, vol. 21, no. 12, pp. 5588-5595, 2005.

[21] A. Houas, H. Lachheb, M. Ksibi, E. Elaloui, C. Guillard, and J.M. Herrmann, "Photocatalytic degradation pathway of methylene blue in water," Applied Catalysis B, vol. 31, no. 2, pp. 145-157, 2001. 
[22] P. Reeves, R. Ohlhausen, D. Sloan et al., "Photocatalytic destruction of organic dyes in aqueous $\mathrm{TiO}_{2}$ suspensions using concentrated simulated and natural solar energy," Solar Energy, vol. 48, no. 6, pp. 413-420, 1992.

[23] R. W. Matthews, "Photooxidative degradation of coloured organics in water using supported catalysts. $\mathrm{TiO}_{2}$ on sand," Water Research, vol. 25, no. 10, pp. 1169-1176, 1991.

[24] M. Kerzhentsev, C. Guillard, J.-M. Herrmann, and P. Pichat, "Photocatalytic pollutant removal in water at room temperature: case study of the total degradation of the insecticide fenitrothion (phosphorothioic acid O,O-dimethyl-O-(3-methyl-4nitro-phenyl) ester)," Catalysis Today, vol. 27, no. 1-2, pp. 215220, 1996.

[25] Y.-H. Xu, H.-R. Chen, Z.-X. Zeng, and B. Lei, "Investigation on mechanism of photocatalytic activity enhancement of nanometer cerium-doped titania," Applied Surface Science, vol. 252, no. 24, pp. 8565-8570, 2006.

[26] V. Vuppala, M. G. Motappa, S. S. Venkata, and P. H. Sadashivaiah, "Photocatalytic degradation of methylene blue using a zinc oxide-cerium oxide catalyst," European Journal of Chemistry, vol. 3, no. 2, pp. 191-195, 2012.

[27] J. Bennani, R. Dillert, T. M. Gesing, and D. Bahnemann, "Physical properties, stability, and photocatalytic activity of transparent $\mathrm{TiO}_{2} / \mathrm{SiO}_{2}$ films," Separation and Purification Technology, vol. 67, no. 2, pp. 173-179, 2009.

[28] R.-A. Doong, C.-H. Chen, R. A. Maithreepala, and S.-M. Chang, "The influence of $\mathrm{pH}$ and cadmium sulfide on the photocatalytic degradation of 2-chlorophenol in titanium dioxide suspensions," Water Research, vol. 35, no. 12, pp. 2873-2880, 2001.

[29] L. Rideh, A. Wehrer, D. Ronze, and A. Zoulalian, "Photocatalytic Degradation of 2-Chlorophenol in $\mathrm{TiO}_{2}$ Aqueous Suspension: modeling of Reaction Rate," Industrial and Engineering Chemistry Research, vol. 36, no. 11, pp. 4712-4718, 1997.

[30] R. Fretwell and P. Douglas, "An active, robust and transparent nanocrystalline anatase $\mathrm{TiO}_{2}$ thin film-preparation, characterisation and the kinetics of photodegradation of model pollutants," Journal of Photochemistry and Photobiology A, vol. 143, no. 2-3, pp. 229-240, 2001.

[31] M. Addamo, V. Augugliaro, A. Di Paola et al., "Photocatalytic thin films of $\mathrm{TiO}_{2}$ formed by a sol-gel process using titanium tetraisopropoxide as the precursor," Thin Solid Films, vol. 516, no. 12, pp. 3802-3807, 2008.

[32] N. M. Mahmoodi, "Photocatalytic degradation of dyes using carbon nanotube and titania nanoparticle," Water, Air, \& Soil Pollution, vol. 224, p. 1612, 2013.

[33] I. K. Konstantinou and T. A. Albanis, " $\mathrm{TiO}_{2}$-assisted photocatalytic degradation of azo dyes in aqueous solution: kinetic and mechanistic investigations: a review," Applied Catalysis B, vol. 49, no. 1, pp. 1-14, 2004. 

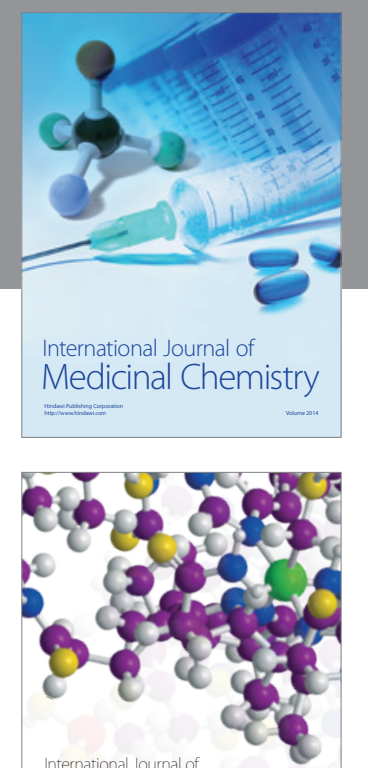

\section{Carbohydrate} Chemistry

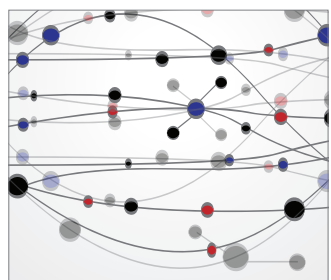

The Scientific World Journal
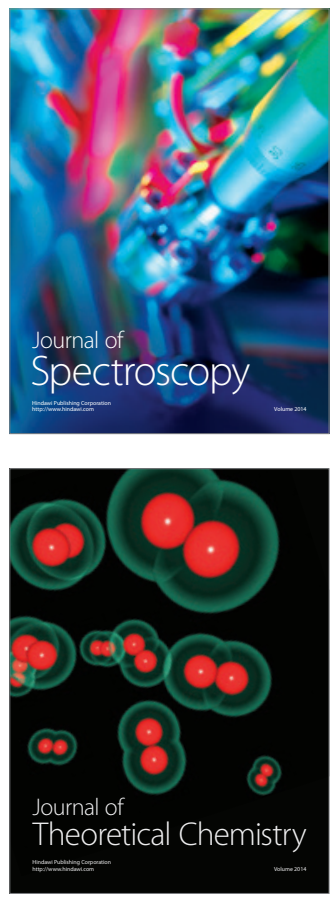
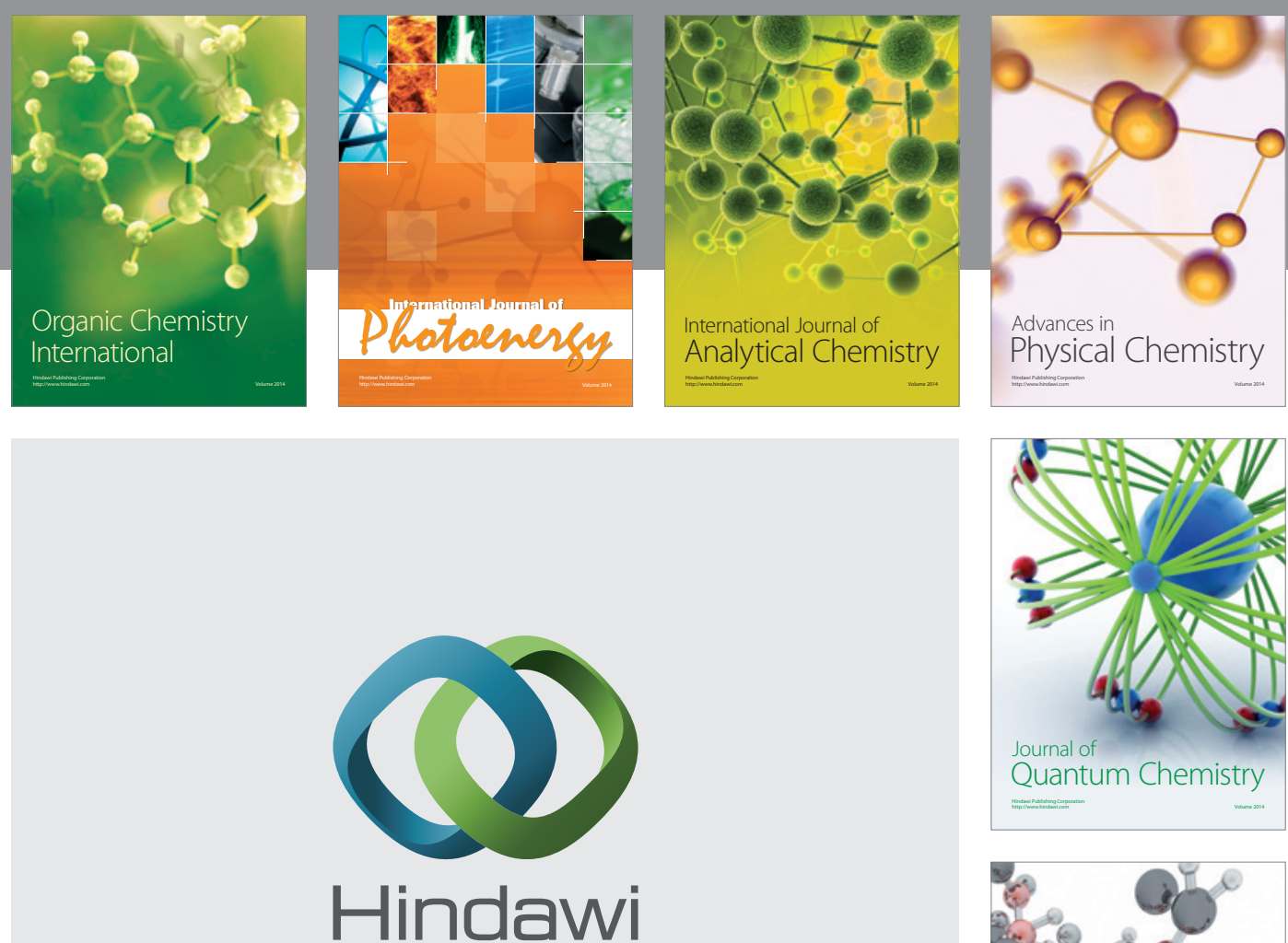

Submit your manuscripts at

http://www.hindawi.com

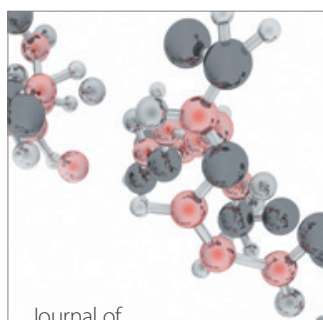

Analytical Methods

in Chemistry

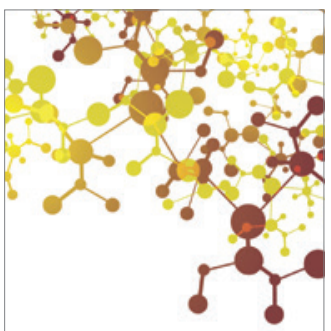

Journal of

Applied Chemistry

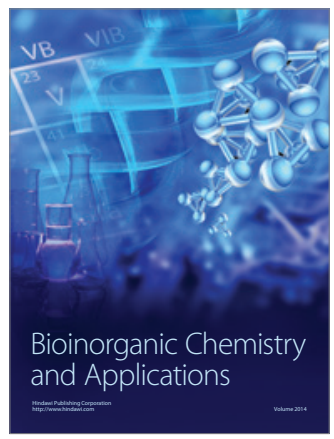

Inorganic Chemistry
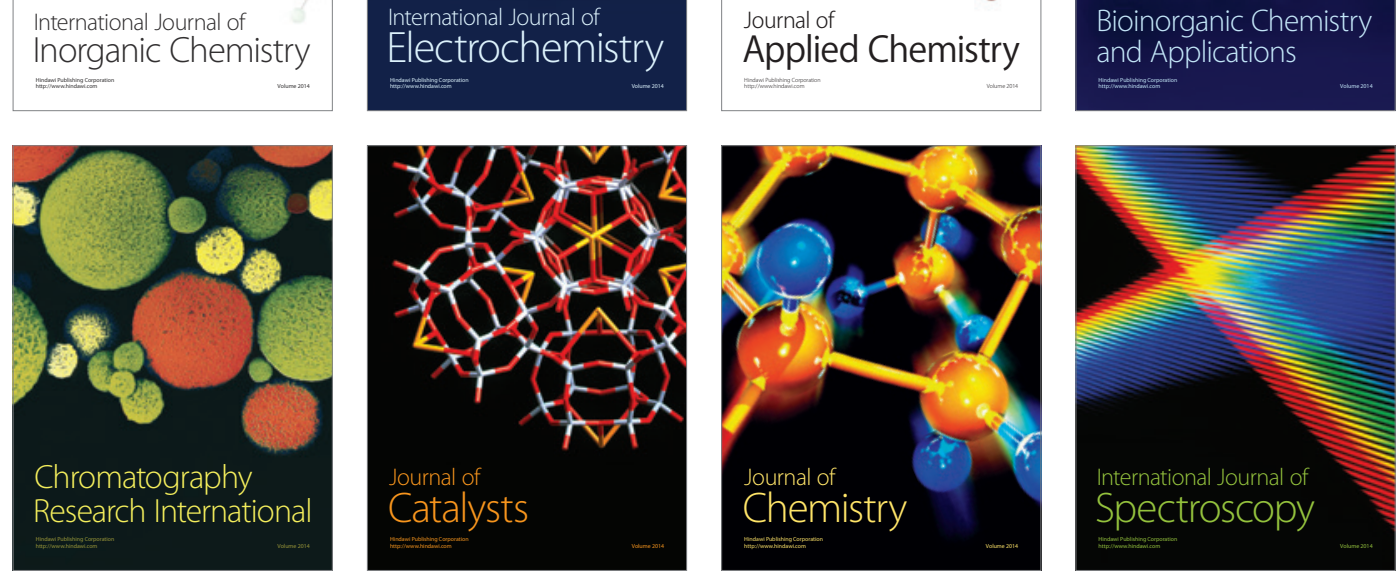